\title{
Quantitative analysis of heart rate variability exposures in motorbike riders.
}

\author{
Ramasamy $S^{1,2^{*}}$, Adalarasu $K^{3}$, Trupti Patel $^{2}$ \\ ${ }^{1}$ Department of E \& C Engineering, Manipal Institute of Technology, Manipal Academy of Higher Education, Manipal, \\ India \\ ${ }^{2}$ School of Biosciences \& Technology, VIT, Vellore, India \\ ${ }^{3}$ School of E \& E Engineering, SASTRA, Thanjavur, Tamil Nadu, India
}

\begin{abstract}
Heart Rate Variability (HRV) has been a growing major health concern worldwide. It is a key factor to determine an individual's cardiovascular condition. The imbalance in the heart rate has profound impact in causation of several heart diseases. This study aimed to investigate the HRV risk factors that are predominant in the development of heart diseases in motorbike riders. It involves 10 healthy subjects riding five different Indian make motorbikes. Photo plethysmography signal was recorded in three different conditions such as before, during and after motorbike riding using pulse oximeter. The acquired physiological signals from different motorbike riders were processed to determine the variability in the heart rate. The parameters such as systolic amplitude, diastolic amplitude and dicrotic notch for all considered motorbikes were extracted. The results of this study shows an exceptionally high risks of variation in the heart rate among motorbike riders for vehicles having overall kerb weight of $187 \mathrm{~kg}$, moderate risks for kerb weight between 144-145 kg and low risks for motorbikes having kerb weight between 132-137 kg. Body vibration too had an impact on the heart rate variability. Our study thus, reveals that existence of abnormal HRV owing to increase in motorbike kerb weight and speed. The other factors such as vehicle suspension, body design and wheels dimension also indirectly influences HRV. We suggest that essential ergonomic interventions are required to eliminate HRV exposure risks in motorbikes.
\end{abstract}

Keywords: Motorbike riders, Heart rate variability (HRV), Photo plethysmography, Pulse oximeter, Ergonomics. Accepted on March 30, 2018

\section{Introduction}

According to the study conducted by the International Congestive Heart Failure (INTER-CHF) in 2017, heart attacks claim $15 \%$ of cumulative mortality from South East Asian countries, which is on the higher side when compared to other Asian and American countries [1]. Based on the reports of All India Institute of Medical Sciences (AIIMS) and Indian Council of Medical Research (ICMR) in the year 2017, young Indian population below the age group of 30 are more prone to heart conditions which are an alarming revelation. The imbalance variation in heart rate leads to the occurrence of several diseases such as heart failure, hypertension and diabetes [2-7]. Functional strength, gender and age have a greater impact during HRV measurements [2].

Heart rate variability is the fluctuation in the time between consecutive heartbeats. In order to evaluate the efficiency of the cardiovascular system, measurement of HRV is needed. Heart rate varies throughout the process of respiration. Ideally 65 to 75 beats per min (bpm) is the pulse rate for a healthy human being [8]. Pulse rate higher than 75 beats while resting are considered as risk of occurrence of heart diseases. By Karvonen protocol, the Maximum Heart Rate (MHR) is calculated from the difference between 220 and the age of the rider. The normal heart rate for a motorbike rider is considered as 93 to $157 \mathrm{bpm}$ for the age group of 18 and above and anything above $157 \mathrm{bpm}$ is considered as an unusual pulse rate. Vehicle body vibration, kerb weight, suspension, vehicle body design and wheel dimensions are the most important vehicle parameters responsible for $\mathrm{HRV}$ and driving related musculoskeletal disorders [9]. The abnormal pulse rate variation is also associated with personal factors such as stress and anomalous food intake and lifestyle.

Photo plethysmography is an accurate non-invasive method to measure pulse rate and oxygen saturation [10]. The HRV is measured in the finger where the blood vessels are closer to the skin using Pulse oximeter. The Pulse oximeter is a portable, compact and low power consuming device. In order to evaluate HRV, the study subjects need to keep right index finger into the pulse oximeter for measurement. In the present study, the imbalance in the heart rates were measured under three conditions: i) Before riding; ii) During riding; iii) After riding 
for $240 \mathrm{~s}$ respectively. The aim of this work was to aid the vehicle ergonomists to determine the intervention strategies to overcome the imbalances in the heart rate, is any due to riding. The assessment of heart rate and along with oxygen saturation levels has been shown to aid diagnosis in healthcare, and study the stamina and output in sports.

Raw PPG signals are time domain signals. i.e., the PPG signals are represented with respect to time and amplitude in raw format. The most distinguished evidence is hidden in the frequency content of the signal. Fast Fourier Transform (FFT) is used to determine the frequency information from the acquired time domain PPG signal. Change in the posture shows the variation in the low frequency components of the PPG waveform $[11,12]$. However in the current study, we evaluate quantitatively the HRV risk factors that are pervasive in the development of heart diseases in motorbike riders. The data collected from the study will aid the health practitioners and vehicle design ergonomists to define the intervention approaches to eliminate HRV risks in motorbike riders.

\section{Materials and Methods}

\section{Subjects}

This study was intended to collect HRV measurements from the 10 participants divided from an equal number of male and female drivers who drive five dissimilar Indian made motorbikes in the sub-continent of India's southern zone where $70 \%$ of the overall populace are motorbike riders. The minimum legal permissible age to drive a motorbike is $18 \mathrm{y}$. All the participants were informed about the purpose of study and all of them were within the age group of 18 to $40 \mathrm{y}$. The subjects were asked to read and signed an informed consent form before participation. The subjects having the habit of smoking, previous illness such as hypertension, diabetes, blood pressure and stress were not considered for the study. The participating subjects were riding motorbike approximately 1 $\mathrm{h} / \mathrm{d}$ and the study was proposed to collect riders heart rate for about $4 \mathrm{~min}$ in the standard permissible speed of $40 \mathrm{~km} / \mathrm{h}$ while riding in the modern Indian highway.

\section{Task}

This task was designed to involve participants divided equally across 5 age groups. The drivers were methodically selected so there was equal representation of all age groups such as 18-20, 21-25, 26-30, 31-35 and 36-40.

The subjective names assigned to different make of motorbike groups were A, B, C, D and E. The motorbikes were selected based on the technical specifications which majorly affects the HRV such as kerb weight, suspension and wheel base. The considered motorbikes are more frequently used motorbikes in Southern region of India. The technical specifications for the motorbikes are shown in Table 1. Each participant was instructed to drive all the motorbikes for HRV assessment.

Pulse oximeter was used to record the PPG signal in three different conditions such as before driving, during riding and after riding for $240 \mathrm{~s}$ respectively. The subjects were asked to keep their right index finger into pulse oximeter probe before, during and after driving. The pulse rate was measured continuously for about $240 \mathrm{~s}$ in each case while driving motorbike in the Indian modern highway. The physiological signals were time dependent. Fast Fourier transform was used to derive the frequency content of the signal. The featured extracted from the raw PPG signal such as systolic amplitude, diastolic amplitude and dicrotic notch was analysed quantitatively to study the relationship between different motorbikes.

Table 1. Technical specifications for the different makes of the motorbike.

\begin{tabular}{llllll}
\hline S no. & Bike A & Bike B & Bike C & Bike D & Bike E \\
\hline Kerb weight & $144 \mathrm{~kg}$ & $145 \mathrm{~kg}$ & $132 \mathrm{~kg}$ & $187 \mathrm{~kg}$ & $137 \mathrm{~kg}$ \\
\hline Seat height & $785 \mathrm{~mm}$ & $785 \mathrm{~mm}$ & $775 \mathrm{~mm}$ & $800 \mathrm{~mm}$ & $790 \mathrm{~mm}$ \\
\hline Suspension & $\begin{array}{l}\text { Telescopic } \\
\text { forks }\end{array}$ & $\begin{array}{l}\text { Telescopic } \\
\text { hydraulic } \\
\text { shock } \\
\text { absorbers }\end{array}$ & $\begin{array}{l}\text { Telescopi } \\
\text { c forks }\end{array}$ & $\begin{array}{l}\text { Telescopi } \\
\text { c forks }\end{array}$ & $\begin{array}{l}\text { Telescopi } \\
\text { c forks }\end{array}$ \\
\hline Wheel base & $1320 \mathrm{~mm}$ & $1230 \mathrm{~mm}$ & $1330 \mathrm{~mm}$ & $1370 \mathrm{~mm}$ & $1300 \mathrm{~mm}$ \\
\hline
\end{tabular}

\section{Statistical analysis}

The PPG data's acquired from pulse oximeter was subjected to statistical analysis of one way ANOVA test to identify the relationship between different motorbikes and the heart rate measurements under three conditions. The calculated $\mathrm{P}$ values were 0.002 and it is considered as statistically significant which is found to be less than 0.01 . The confidence level considered was $95 \%$. The degree of freedom (df) is 2 .

\section{Results and Discussion}

A total of 10 subjects, equally distributed from the age 18 to 40 , voluntarily participated in the assessment. Each participant had to drive all motorbikes and the PPG was recorded under three conditions such as before, during and after driving the motorbike for about $240 \mathrm{~s}$. The features such as systolic amplitude, diastolic amplitude and dicrotic notch for all considered motorbikes were shown in Table 2.

Table 2. Shows feature extracted parameters for different motorbikes.

\begin{tabular}{llll}
\hline Motorbike & $\begin{array}{l}\text { Systolic amplitude } \\
\text { (mean } \pm \text { Std error) }\end{array}$ & $\begin{array}{l}\text { Diastolic amplitude } \\
\text { (mean } \pm \text { Std error) }\end{array}$ & $\begin{array}{l}\text { Dicrotic notch } \\
\text { (mean } \\
\text { error) }\end{array}$ \\
\hline A & $112.3 \pm 1.16$ & $108.3 \pm 1.23$ & $109.9 \pm 1.22$ \\
\hline$B$ & $118.02 \pm 1.25$ & $115.3 \pm 1.25$ & $116.2 \pm 1.25$ \\
\hline C & $94.30 \pm 1.52$ & $91 \pm 1.59$ & $92.61 \pm 1.46$ \\
\hline D & $134.25 \pm 1.88$ & $131.3 \pm 1.96$ & $132.7 \pm 1.94$ \\
\hline E & $99.7 \pm 0.97$ & $96.6 \pm 0.87$ & $97.7 \pm 0.85$ \\
\hline
\end{tabular}


The evaluation of systolic amplitude, diastolic amplitude and dicrotic notch are shown in Figures 1-3. Systolic blood pressure determines the pressure in our blood vessels when heart beats. Below $120 \mathrm{mmHg}$ of systolic blood pressure is considered as normal. Blood pressure more than $140 \mathrm{mmHg}$ is considered as high. Blood pressure in-between 120 and 140 have a condition called prehypertension, which means they are at high risk for heart diseases. Motorbike D has mean systolic pressure of $134.25 \pm 1.88$ have a condition called prehypertension. Prehypertension increases the risk that you will develop chronic, or long-lasting, high blood pressure in the future. The results of motorbike D shows exceptionally high risks of occurrence of prehypertension among motorbike riders. Kerb weight $187 \mathrm{~kg}$ of motorbike D has an impact on the increase in systolic pressure. Motorbike A, B, C and E has normal systolic pressure which falls below $120 \mathrm{mmHg}$ due to its less and moderate kerb weight.

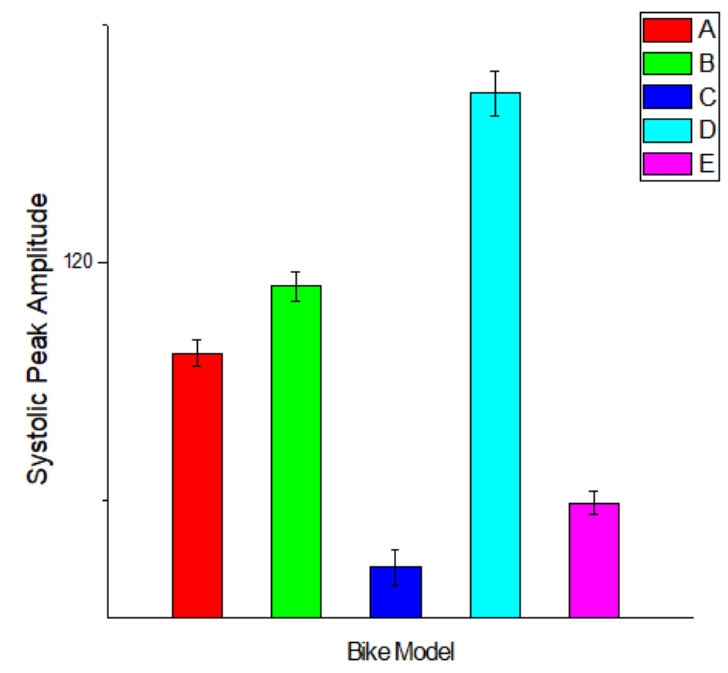

Figure 1. Evaluation of systolic peak amplitude for different motorbike.

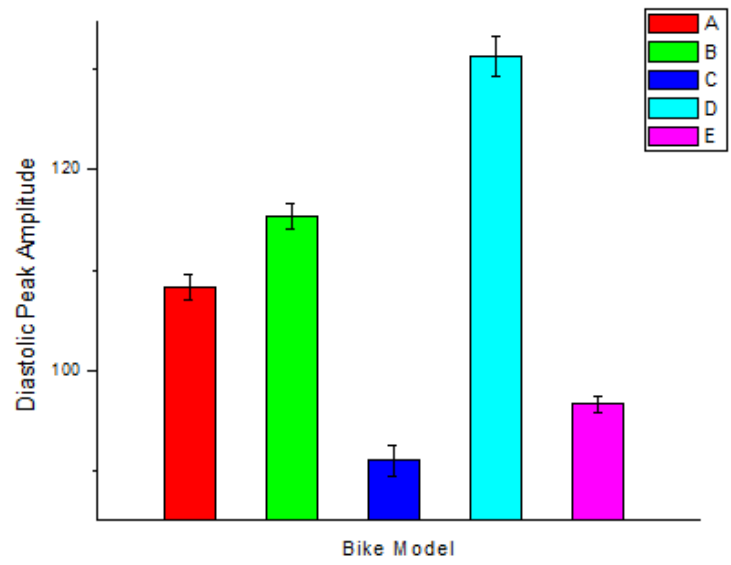

Figure 2. Evaluation of diastolic peak amplitude for different motorbike.
Diastolic blood pressure is the pressure in our blood vessels when heart rests between beats. A diastolic blood pressure less than $80 \mathrm{mmHg}$ is considered as normal. $90 \mathrm{mmHg}$ or more is too high. People with levels in between 80 and 89 have a condition called prehypertension, which means they are at high risk for heart diseases. Motorbike $\mathrm{C}$ has mean diastolic pressure of $91 \pm 1.59$. Bike $\mathrm{A}, \mathrm{B}, \mathrm{D}$ and $\mathrm{E}$ has very high diastolic pressure increases of high risk of occurrence of heart diseases. Study reveals that kerb weight more than $137 \mathrm{~kg}$ are having very high diastolic pressure and are more prone to risks of occurrence of heart diseases.

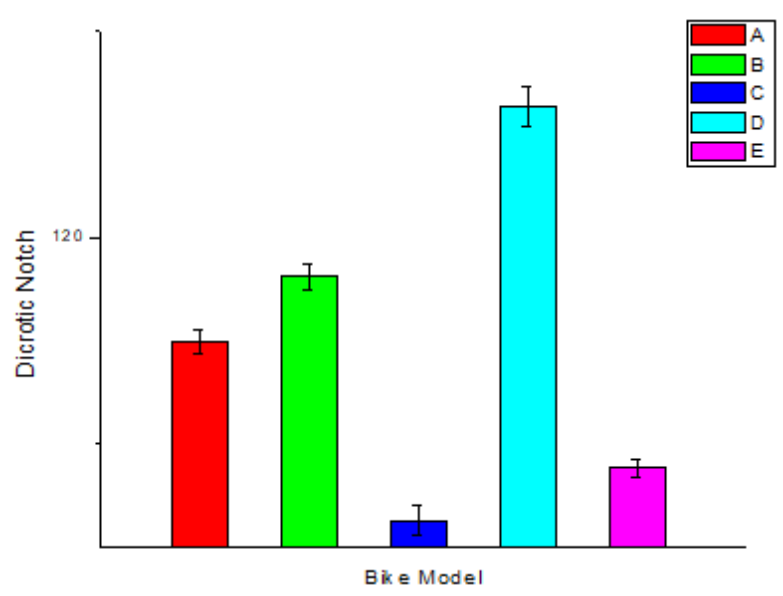

Figure 3. Evaluation of dicrotic notch for different motorbike.

Decrease in the aortic pressure during the cardiac cycle is known as dicrotic notch which coincides with the aortic valve closure. The dicrotic notch depends on the age and gender of the subject. Increase in age of the subject leads to drop in dicrotic notch pulse which further leads to high risk of occurrence of coronary heart disease. The subjects considered are equally distributed among all categories of ages. Hence there is no much effect on dicrotic notch.

The pulse rate was measured continuously for about $240 \mathrm{~s}$ before, during and after riding are shown in Table 3 . The pulse rate measured before riding shows that $81.60 \pm 0.91$ for bike $\mathrm{A}$, $82.57 \pm 2.75$ for bike $\mathrm{B}, 77.62 \pm 2.08$ for bike $\mathrm{C}, 80.66 \pm 1.90$ for bike $\mathrm{D}$ and $79.82 \pm 1.64$ for bike $\mathrm{E}$. The pulse rate during riding is our real concern. HRV assessment during riding reveals that $108.25 \pm 1.98$ for bike $\mathrm{A}, 113.06 \pm 1.75$ for bike $\mathrm{B}$, $87.33 \pm 2.32$ for bike C, $135.36 \pm 4.30$ for bike D and $92.68 \pm$ 1.87 for bike E. Pulse rate after riding shows that $78.90 \pm 1.78$ for bike A, $79.64 \pm 1.37$ for bike $\mathrm{B}, 72.67 \pm 1.03$ for bike $\mathrm{C}$, $83.23 \pm 0.462$ for bike $\mathrm{D}, 75.30 \pm 1.75$ for bike $\mathrm{E}$. The analysis of acquired PPG results found that there was a huge imbalance in the heart rate when the subjects were driving Bike D. Our results showed that bike $\mathrm{A}$ and $\mathrm{B}$ had moderate variation in the heart rate and Bike $\mathrm{C}$ and $\mathrm{E}$ had low Heart Rate (HR) variation. Based on one way ANOVA test, the comparison between different motorbikes found that the $\mathrm{p}$ value is equal to 0.002 and it is significant at $\mathrm{p}<0.01$. The average heart rate of the subject was determined for $240 \mathrm{~s}$. Our experimental analysis 
further reveals there is a significant association between the motorbike kerb weight and the heart rate variability.

Table 3. Acquired HRV parameters from different motorbikes using pulse oximeter.

\begin{tabular}{|c|c|c|c|c|c|c|}
\hline S no. & Parameters & $\begin{array}{l}\text { Bike A (Mean } \pm \\
\text { Standard error) }\end{array}$ & $\begin{array}{l}\text { Bike B (Mean } \pm \\
\text { Standard error) }\end{array}$ & $\begin{array}{l}\text { Bike C (Mean } \pm \\
\text { Standard error) }\end{array}$ & $\begin{array}{l}\text { Bike D } \\
\text { Standard error) }\end{array}$ & $\begin{array}{l}\text { Bike E (Mean } \pm \\
\text { Standard error) }\end{array}$ \\
\hline 1 & $\begin{array}{l}\text { Pulse rate before riding } \\
\text { for } 240 \mathrm{~s}\end{array}$ & $81.60 \pm 0.91$ & $82.57 \pm 2.75$ & $77.62 \pm 2.08$ & $80.66 \pm 1.90$ & $79.82 \pm 1.64$ \\
\hline 2 & $\begin{array}{l}\text { Pulse rate during riding } \\
\text { for } 240 \mathrm{~s}\end{array}$ & $108.25 \pm 1.98$ & $113.06 \pm 1.75$ & $87.33 \pm 2.32$ & $135.36 \pm 4.30$ & $92.68 \pm 1.87$ \\
\hline 3 & $\begin{array}{l}\text { Pulse rate after riding for } \\
240 \mathrm{~s}\end{array}$ & $78.90 \pm 1.78$ & $79.64 \pm 1.37$ & $72.67 \pm 1.03$ & $83.23 \pm 0.462$ & $75.30 \pm 1.75$ \\
\hline
\end{tabular}

Imbalances in the heart rate variation are also termed as arrhythmia. HRV is also used to assess autonomic imbalances. There is a significant relationship between cardiovascular mortality and autonomic nervous system [13,14]. Imbalances in the heart rate may be the indication of pre-existing or awaiting cardiac diseases [15]. The occasional imbalances in the HR may occur during certain durations of the day [15]. The continuous monitoring of pulse rate is very much important. The driver's personal factors such as smoking, stress, anxiety, previous illnesses such as hypertension, diabetes, blood pressure, anxiety and stress largely responds to HRV [13]. The heart rate can give information about the state of mind during cognitive evaluations [16].

The relationship between kerb weight and Heart rate variability factors during riding is shown in Figure 4. Further analysis of the HR between motorbikes reveals that Bike D had huge variation in the pulse rate between before, during and after driving; Bike D has a kerb weight of $187 \mathrm{~kg}$, which is very high when compared to the other motorbikes considered for the study. Due to increase in kerb weight, vehicle body vibration increases to an extent, induces the imbalance in the heart rate. Bike A and B has kerb weight between 144 to $145 \mathrm{~kg}$. HRV risk exposures to bike $\mathrm{A}$ and bike $\mathrm{B}$ is found to be moderate owing to its moderate weight. Bike $\mathrm{C}$ and $\mathrm{E}$ has kerb weight between 132-137 kg. Analysis for Bike $\mathrm{C}$ and $\mathrm{E}$ reveals low HRV risks due to its less weight. Increase in kerb weight and vehicle vibration creates imbalances in heart rate.

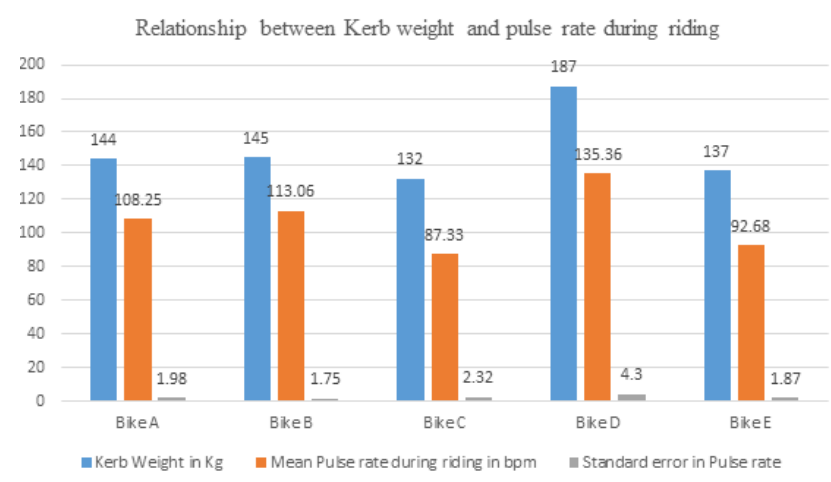

Figure 4. Relationship between kerb weight and pulse rate during riding.
Based on the analysis of our observed results we conclude that technical specifications such as kerb weight and body vibration play an important role in heart beat variation. Ergonomic interventions are required to eliminate HRV risks in motorbike riders. Minimizing the vehicle body weight and the body vibration drastically reduces the imbalances in the heart rate. It also minimizes the occurrence of heart diseases.

\section{Conclusion}

Motorbike riders are suggested as target population for the assessment of the heart rate variability. The present study explored the variation of physiological signals in the motorbike riders. The prevalence of occurrence of heart diseases among motorbike riders have been reported higher in bike which has more kerb weight and body vibration. The main implication of the current study is to pay special attention to the motorbike technical specifications and to help the vehicle ergonomists to intervene the vehicle body design to minimize the heart rate variability, human health and well-being.

\section{Acknowledgement}

The authors would like to thank the management of Manipal Institute of technology and VIT Vellore for providing required facilities to carry out this work.

\section{References}

1. Hisham D, Koon T, Jun Z, Ambuj R, Khalid FA, Ahmed E, Lia P-V, Patricio L-J, Kamilu K, Khalid Y, Andres O, Karen S, Charles M, Fernando L, Dorairaj P, Amr B, Mohamed E, Albertino D, Kemi T, Emilie B-Ce, Kumar B, Shofiqul I, Magdi HY, Mark DH, Karen H, Alex G, Robert MK, Shrikant IB, Salim Y. Global mortality variations in patients with heart failure: results from the International Congestive Heart Failure (INTER-CHF) prospective cohort study. The Lancet J 2017; 5: 665-672.

2. Shamir NK, Alberto S, Shaun MM, Gareth LA. Heart rate variability in critical care medicine: a systematic review. Intensive Care Med Exp 2017; 5: 1-15.

3. Buccelletti E, Gilardi E, Scaini E, Galiuto L, Persiani R, Biondi A, Basile F, Silveri NG. Heart rate variability and myocardial infarction: systematic literature review and 
metanalysis. Eur Rev Med Pharmacol Sci 2009; 13: 299-307.

4. Nolan J, Batin PD, Andrews R, Lindsay SJ, Brooksby P, Mullen M, Baig W, Flapan AD, Cowley A, Prescott RJ, Neilson JM, Fox KA . Prospective study of heart rate variability and mortality in chronic heart failure: results of the United Kingdom heart failure evaluation and assessment of risk trial (UK-heart). Circulation 1998; 98: 1510-1516.

5. Bilchick KC, Fetics B, Djoukeng R, Fisher SG, Fletcher RD, Singh SN, Nevo E, Berger RD. Prognostic value of heart rate variability in chronic congestive heart failure (Veterans affairs' survival trial of antiarrhythmic therapy in congestive heart failure). Am J Cardiol 2002; 90: 24-28.

6. Stuckey MI, Petrella RJ. Heart rate variability in type 2 diabetes mellitus. Crit Rev Biomed Eng 2013; 41: 137-147.

7. Singh JP, Larson MG, Tsuji H, Evans JC, O'Donnell CJ, Levy D. Reduced heart rate variability and new-onset hypertension: insights into pathogenesis of hypertension: the Framingham Heart Study. Hypertension 1998; 32: 293-297.

8. de Santos Sierra A, Avila CS, Casanova JG, del Pozo GB. A stress-detection based on physiological signals and fuzzy logic. IEEE Transactions on Industrial Electronics 2011; 58: 10.

9. Ramasamy S, Adalarasu K, Trupti NP. Evaluation of driving-related musculoskeletal disorders in motorbike riders using Quick Exposure Check (QEC). Biomed Res 2017; 28: 1962-1968.

10. Sasikumar K, George Priya Doss C, Adalarasu K. Analysis of physiological signal variation between autism and control group in South Indian population. Biomed Res 2015; 26: 525-529.
11. Cvetkovic D, Ubeuli ED, Cosic I. Wavelet transform feature extraction from human PPG, ECG and EEG signal responses to ELF PEMF exposures: A pilot study. Digital Signal Processing 2008; 18: 861-874.

12. Bernardi L, Radaelli A, Solda PL, Coats AJS, Martin R, Alessandro C, Christopher SG, Peter S. Autonomic control of skin microvessels: assessment by power spectrum of photoplethysmographic waves. Clin Sci 1996; 90: 345-356.

13. De JJ, Logier R, Jounwaz R, Vidal R, Jeanne M. From pain to stress evaluation using heart rate variability analysis: development of an evaluation platform. 32nd Annual International Conference of the IEEE EMBS 2010.

14. Task Force of the European Society of Cardiology and the North American Society of Pacing and Electrophysiology. Heart rate variability. Euro Heart J 1996; 17: 354-381.

15. Hoang CD, Kien NP, Dung NV. A review of heart rate variability and its applications. APCBEE Procedia 2013; 7: 80-85.

16. de santos Sierra A, Avila CS, Casanova JG, del Pozo GB. A stress-detection system based on physiological signals and fuzzy logic. IEEE Transactions on Industrial Electronics 2011; 58: 10.

\section{*Correspondence to}

Ramasamy S

Department of E \& C Engineering

Manipal Institute of Technology

Manipal Academy of Higher Education

Manipal

India 